\title{
Erratum: Characteristics and predictive biomarkers of drug resistant epilepsy -- study in Georgia
}

\author{
Neuroimmunology and Neuroinflammation Editorial Office \\ Correspondence to: OAE Publishing Inc. 245 E Main Street st122, Alhambra, CA 91801, USA. \\ E-mail: editor001@nnjournal.net \\ Received: 3 Sep 2018 Accepted: 3 Sep 2018 Published: 6 Sep 2018
}

DOI: $10.20517 / 2347-8659.2018 .54$

The Neuroimmunology and Neuroinflammation Editorial Office would like to report an abbreviation-related error in the published article $\mathrm{e}^{[1]}$.

The first sentence of paragraph 2 in Introduction part "Approximately $2 / 3$ of patients with epilepsy become seizure-free following correct diagnosis and on appropriate treatment with antiepileptic drugs automated external defibrillator (AED)" has been replaced by "Approximately $2 / 3$ of patients with epilepsy become seizure-free following correct diagnosis and on appropriate treatment with antiepileptic drugs (AED)".

During the production, there was a mistake in matching up the abbreviation "AED" with corresponding words and it has been corrected. We apologize for any inconvenience caused to the readers by this change. The change does not affect the scientific results.

The original article was published on 27 Sep 2017.

\section{REFERENCE}

1. Alkhidze M, Lomidze G, Kasradze S, Tsiskaridze A. Characteristics and predictive biomarkers of drug resistant epilepsy -- study in Georgia. Neuroimmunol Neuroinflammation 2017;4:191-8. 